\title{
correspondence
}

\section{Dangers of low doses of radiation}

SIR, - David Dickson's account (19 July, page 180) of the controversies surrounding the BEIR III report is evidently a fair and unusually competent job of science reporting. However, it should be made clear that the disagreement on the validity of the "linear hypothesis" when applied to carcinogenesis by low LET radiation does not, strictly speaking, concern the "filling" of a "gap". This terminology might be interpreted to indicate an interpolation while there is in fact the need for (much more uncertain) extrapolation. it is the magnitude of the risk at about $0.1 \mathrm{~Gy}(10$ rad) that is in dispute. As stated by Dickson, there is agreement on even greater uncertainties at lower doses. I, for one, could not object to various surmises (including linear extrapolations) on what might happen below that level in view of the virtual absence of acceptable data on the carcinogenetic effects, if any, of such small doses.

By contrast, information on high LET radiations, and especially the data for Hiroshima, where neutrons plainly posed the principal hazard, indicates approximate linearity down to doses less than $0.1 \mathrm{~Gy}$.

It should also be borne in mind that any fit of the data by linear or quadratic functions is probably at best a first approximation. Animal experiments show complicated - and sometimes inverse - correlations between radiation dose and carcinogenesis which vary not only between species and strains, but also between types of cancer. It would seem unrealistic to assume that the same does not apply to man.

Radiological Research Laboratory, HaRALD H. Ross Columbia University, New York, US.

\section{Nautilus records Earth's second moon}

SIR, - I quite understand the need to close the debate on the fascinating Kahn-PompeaRuncorn dialogue concerning the possibility that Nautilus has quietly recorded the lunar recession rate through the ages ( 31 May, page 452). However, it should be noted that (as in many debates) the participants, including Nautilus, may be arguing from different premises. That is to say, while Pompea, Kahn, and Runcorn are clearly discussing our present moon, let us say Luna, Nautilus may in fact have recorded the recession of a sister moon, let us say Selena, from Ordovician until rather recent geological time.

If Selena had been in orbit at 12 Earth radii in Ordovician time, as Pompea and Kahn propose for Luna, she could have dominated the Nautilus recording apparatus even with a mass much less than her sister Luna, who could well have been orbiting far out near her present position of 60 Earth radii. Perhaps a later Precambrian continental emergence had greatly increased tidal fricition, so that lightweight Selena, receding from the Earth at the required ten-times greater rate than that of present-day Luna, finally approached her sister too closely, and was either devoured by collision or ejected to the firmament. In any event, a small Selena could have orbited the Earth more closely, and have retreated much more rapidly than her larger sister, without dumping the excessive heat noted by Runcorn into the Earth-Luna system.

If Selena vanished before mid-Tertiary, then Runcorn's objection that there is no record of the maxiumum 33-day month which Luna should have produced at 45 Earth radii is of no concern; Luna would have been far beyond that orbit when she took over regulation of the Nautilian cycle, leaving every vestige of Selena forgotten except for a few shells and perhaps a very-young lunar mascon.

It is worth noting that $\mathrm{H}$. Alfven and $\mathrm{G}$. Arrhenius (Evolution of the Solar System, NASA, 1976) have proposed, by analogy with the Martian satellites, that Earth once had a second moon at a predicted orbital distance of 13.5 Earth radii, very close to the inferred Nautilian Ordocician value of 12 . Perhaps Selena finally perished simply because Earth had oceans of water; the persistence of two Martian satellites may thus mean that Mars has never had an ocean at all.

HARMON CRAIG Scripps Institution of Oceanography, La Jolla, California, US.

\section{Nuclear power: an evil necessity for some countries}

SIR, - In a letter under the title "Nuclear power does not lead to nuclear weapons" (5 July, page 10), Mr Greenhalgh, speaking for the nuclear lobby group "A Power for Good", argues that there is no direct link between peaceful nuclear power and nuclear weapons. It is tragic that in this day and age such absurd views should be advanced, which fly in the face of convictions held by the majority of nations. The Non-Proliferation Treaty and the safeguard systems of the International Atomic Energy Agency are the best evidence of the concern which people al over the world have for years felt about the link between nuclear power and nuclear weapons. More recently, and in recognition of the weaknesses and shortcomings of the NPT and the safeguards systems, a number of new initiatives were taken. The London Club was set up to provide additional guarantees. The International Nuclear Fuel Cycle Evaluation, with 56 nations participating, is still studying ways and means of reducing the danger of proliferation arising from the use of nuclear power. In the United States a special act was brought into being for the same purpose. Why would this enormous effort be needed if there were no danger of nuclear power leading to nuclear weapons proliferation?

Mr Greenhalgh bases his argument on past history, that countries developed nuclear weapons before starting nuclear power programmes. But the fact that something has not happened in the past cannot be used as an argument that it will not happen in the future, particularly if the opportunities for it were greatly increased. One of the chief characteristics of beings endowed with thinking power is that they can look ahead, anticipate possible trouble and take steps to prevent it.

A nation could, of course, obtain nuclear weapons by means other than power reactors, but the existence of one danger does not justify the introduction of another danger. Moreover, the setting up of a nuclear power programme, while not being a pre-requisite, is the most likely route to the acquisition of nuclear weapons, because the technology and the materials become legitimately available to a nation possessing nuclear facilities, including a reprocessing or an enrichment plant.

Mr Greenhalgh points to the existence of $100,000 \mathrm{MWe}$ of nuclear power in the world as evidence of no direct link with nuclear weapons, but he forgot to add that this contributes less than 1\% to the world's annual energy consumption. The situation would be radically changed if nuclear power increased by two orders of magnitude, as it would have to do (to meet the energy needs of the developing countries) in order to become the chief source of energy as envisaged by $\mathbf{M r}$ Greenhalgh and his ilk.

Fortunately this is not likely to happen. The danger of proliferation, together with other well known negative aspects of nuclear power as recently illustrated by the Three Mile Island accident, have now convinced public opinion that, at most, nuclear energy should be considered an evil necessity for some countries. Except for those with a vested interest, very few now believe that nuclear energy is a power for good.

London, UK.

\section{Democracy cannot be defended by security police}

SIR, - " "Just imagine yourself sitting there below the judges' table . . . squashed like a lemon'. 'Just tell us, are you a communist?'. 'What do you think of the GDR?'. 'If as a christian you are an anti-fascist - should you not be anti-communist as well?' 'As a christian, you say love your neighbour. But how about the fascists?'."

These quotations come from the official report mentioned in Nature (31 May, page 363 ), which to your correspondent has been "cleverly invented by leftist totalitarians". They are in fact excerpts from the questions asked of Heinrich Haberlein, a pacifist who was found by the constitutional courts unfit to be a teacher, because "while not belonging to those groups hostile to the constitution, his employment could be rejected, if he, while not actively combating the free and democratic constitution, could be reasonably supposed to be simply indifferent towards the latter." (Page 37 of the DGVT report). I suppose that this is an example of what your correspondent calls the 'right to select', and it is of little surprise that the German Society for Behaviour Therapy's report carries the results of this policy.

Your correspondent seems to miss the point that you don't defend democracy by creating a vast security police to hound out "totalitarian radicals' because you intimidate and pollute its concept.

Edinburgh, UK 